\title{
COMPATIBILIDADE DE LECAN ICILLIUM LECANII (HYPHOMYCETES), EM CONDIÇÕES DE LABORATÓRIO E ESTUFA, AOS AGROTÓXICOS UTILIZADOS NA CULTURA DO CRISÂNTEMO
}

\section{I.M. Wenzel, A. Batista Filho, M.H. Gassen, A.M.B. de Almeida}

Instituto Biológico, Laboratório de Controle Biológico, CP 70, CEP 13001-970, Campinas, SP, Brasil. E-mail: iawenzel@yahoo.com.br

\section{RESUMO}

\begin{abstract}
Este trabalho teve como objetivo avaliar, em condições de laboratório e estufa, a compatibilidade de Lecanicillium lecanii, JAB 02, com agrotóxicos. A compatibilidade em laboratório foi verificada misturando-se os agrotóxicos ao meio de cultura BDA e os parâmetros utilizados para a avaliação foram: crescimento vegetativo, esporulação e viabilidade do entomopatógeno. Em condições de estufa, as suspensões dos agrotóxicos e, posteriormente, a do fungo foram pulverizadas em plantas de crisântemo. Após a aplicação, folhas foram coletadas e lavadas obtendo-se uma suspensão que foi plaqueada em BDA, sendo então avaliado o crescimento das colônias do fungo. Verificou-se, em laboratório, que a maioria dos inseticidas e os acaricidas foram compatíveis ao fungo, com exceção do inseticida Thiodan ${ }^{\circledR}$ classificado como muito tóxico. Todos os fungicidas testados foram classificados como tóxico e muito tóxico. Em condições de estufa, no tratamento com o fungicida Rovral ${ }^{\circledR}$ foi observado um número de colônias fúngicas formadas compatível com a testemunha, não afetando o desenvolvimento do fungo. Essa compatibilidade repetiu-se para os produtos Alto $100^{\circledR} \mathrm{e}$ Thiodan ${ }^{\circledR} \mathrm{em}$ alguns dos tempos avaliados. Os produtos Rovral $^{\circledR}$ e Alto $100^{\circledR}$ podem ser utilizados, conjuntamente, quando aplicados previamente ao entomopatógeno.
\end{abstract}

PALAVRAS-CHAVE: Fungo entomopatogênico, ornamentais, controle microbiano.

\section{ABSTRACT}

COMPATIBILITY OF LECANICILLIUM LECANII, IN LABORATORY AND GREENHOUSE CONDITIONS, TO PESTICIDES USED IN THE CHRYSANTHEMUM CROP. The objective of this study was to evaluate, under laboratory and greenhouse conditions, the compatibility of Lecanicillium lecanii, JAB 02, with pesticides. The compatibility in the laboratory was verified adding pesticides to the PDA media and evaluating the parameters of vegetative growth, sporulation and viability of the entomopathogen. In the greenhouse, L. lecanii were sprayed on chrysanthemum plants after the spraying of the pesticides; subsequently, four leaves of each treatment were collected and washed to obtain a suspension that was transfered to PDA medium to evaluate the growth of the fungus colonies in laboratory conditions. The acaricides and most of insecticides were compatible to the isolate JAB 02, except the insecticide Thiodan ${ }^{\circledR}$, which was classified as very toxic. All the evaluated fungicides were classified as toxic or very toxic. In greenhouse assays, the fungicide Rovral ${ }^{\circledR}$ produced a number of grown colonies similar to those of the control, not affecting fungus growth. This compatibility was also shown by the products Alto $100^{\circledast}$ and Thiodan ${ }^{\circledR}$ in some of the evaluated periods. Rovral ${ }^{\circledast}$ and Alto $100^{\circledast}$ can be used, combined, when applied before the entomopathogen.

KEY WORDS: Entomopathogenic fungi, ornamentals, microbial control.

\section{INTRODUÇÃO}

Os fungos entomopatogênicos são inimigos naturais que podem ser diretamente prejudicados pelouso de agrotóxicos, que tem sido a estratégia básica de suprimir as populações de insetos considerados pragas (CAVAlCANTi et al., 2002). A ação dos agrotóxicos sobre os entomopatógenos pode variar em função da espécie elinhagem do patógeno, da natureza química dos produtos e das dosagens utilizadas (Alves, 1998). Esses produtos podem causar inibição do crescimento vegetativo, da conidiogênese ou esporulação, além da viabilidade, patogenicidade evirulência doconídio (CAvalcanti et al., 2002). 
A aplicação combinada de micoinseticidas e agrotóxicos pode ser uma associação positiva, visto que o fungo e o inseticida químico podem atuar sinergisticamente permitindo o uso de concentrações menores de agrotóxicos e a redução na possibilidade de evolução de resistência das pragas (BOMAN, 1980). As combinações podem ser vantajosas em alguns casos, como quando a ação isolada do microrganismo não é totalmente satisfatória (BENZ,1971). A interação entre agrotóxicos e entomopatógenos deve ser considerada antes da recomendação do agente químico e representa uma importante ferramenta nos programas de MIP (BATista Filho et al., 2001).

Vários autores vêm realizando trabalhos sobre a compatibilidade de agrotóxicos e entomopatógenos em laboratório (CAVALCANTIet al., 2002; LOUREIRO et al., 2002; Tamai et al, 2002; Batista Filho et al., 2003; Duran et al., 2004; CinTRA, 2004; ER; GÖKÇE, 2004). Por outro lado, em condições de estufa, esses estudos são escassos, embora de extrema importância, pois o ambiente da estufa pode favorecer o uso dos fungos como bioinseticidas, visto que certos fatores como temperatura e umidade, podem ser manipulados para o início e manutenção de epizootias. Desta forma, para que possam ser utilizados, há necessidade que sejam compatíveis com outros produtos químicos, pois as principais doenças foliares do crisântemo são controladas com aplicações de fungicidas (GARDNER et al., 1984).

Ocrisântemo écultivado há mais de 2.500 anos na China e atualmente existem mais de 100 espécies e 800 variedades comercializadas no mundo (FonTANA, 2005). Entretanto, por ser cultivado em estufa está mais suscetível ao ataque de diversas pragas e doenças, devido às condições adequadas de temperatura, luminosidade, umidade e abundância de alimento. Dentre as pragas destaca-se o ácaro rajado, Tetranychus urticae, que é responsável por causar danos morfológicos e fisiológicos nas plantas, além de danificá-las visualmente influenciando diretamente no seu preço de comercialização.

Assim, para que as plantas ornamentais brasileiras ganhem espaço no mercado exterior e possam ser exportadas, algumas exigências devem ser respeitadas pelos produtores como a ausência de pragas e de resíduos de agrotóxicos. Então para o cumprimento destas exigências há necessidade da utilização de meios de controle menos agressivos, como o controle microbiano. $\mathrm{O}$ uso de fungos entomopatogênicos já vem sendo utilizado com sucesso na supressão de várias pragas em diferentes culturas.

Lecanicillium lecanii (Hyphomycete,Deuteromycotina) é um fungo oportunista o qual possui ampla gama de hospedeiros, incluindo insetos, ácaros, nematóides e fungos fitopatogênicos (HALL, 1981). Na Europa, os produtos formulados $\mathrm{Mycotal}^{\circledast}$ e Vertalec ${ }^{\circledast}$ já vêm sendo utilizados na produção de crisântemo e outros cultivos em estufas para controle de afídeos, tripes e moscas brancas (NILSSON; GRIPWALL, 1999; VAN DER SCHAAF et al., 1990).

Diante do exposto, o trabalho teve como objetivo avaliar a compatibilidade de agrotóxicos ao fungo Lecanicillium lecanii (Zimm.) Zare \& Gams (classeforma: Hyphomycetes), em condições de laboratório e estufa.

\section{MATERIAL E MÉTODOS}

Para a execução do trabalho foi utilizado o isolado JAB 02 de L. lecanii proveniente do Laboratório de Ecologia de Microrganismos da Faculdade de Ciências Agrárias e Veterinárias/Universidade Estadual Paulista, Jaboticabal, SP, Brasil, e isolado da cochonilha verde Coccus viridis Green (Hemiptera: Coccidae). O fungo, conservado em óleo mineral, foi multiplicado através de repicagens em placas de Petri com meio de cultura sólido BDA (batata, dextrose e ágar), incubados durante 12 dias a 25,5 \pm $0,5^{\circ} \mathrm{C}$ em câmara de germinação B.O.D., para obtenção de culturas jovens com vistas à utilização nos ensaios.

\section{Compatibilidade de Lecanicillium lecanii a agrotóxicos}

\section{Em laboratório}

Foram avaliados 20 agrotóxicos, dentre eles os recomendados (CompêndIo de Defensivos Agrícolas, 1999) e utilizados no controle de pragas e doenças na cultura do crisântemo (Crysantemum morifolium) (Tabela 1). Os produtos que possuem uma faixa de variação na quantidade a ser utilizada foram testados com a menor quantidade (concentração mínima) e a maior quantidade (concentração máxima).

Para a avaliação da compatibilidade, o fungo $L$. lecanii foi repicado em meio de cultura BDA contendo os agrotóxicos na dosagem recomendada pelo fabricante (Tabela 1). O meio de cultura foi autoclavado a $1 \mathrm{~atm}\left(121^{\circ} \mathrm{C}\right)$ por 20 minutos e, antes da solidificação, a uma temperatura de aproximadamente $45^{\circ} \mathrm{C}$, foram acrescentados os produtos. Em seguida, a mistura foi vertida em placas de Petri com $9 \mathrm{~cm}$ de diâmetro e a testemunha foi representada pelo meio de cultura específico sem produto. Após a solidificação do meio, o fungo foi transferido através de três pontos nas placas, com auxílio de uma alça de platina. As placas repicadas foram mantidas em B.O.D. durante 16 dias à temperatura de $25,5 \pm 0,5^{\circ} \mathrm{C}$, umidade relativa em torno de $70 \%$ e fotoperíodo de 12 horas. 
Tabela 1 - Agrotóxicos recomendados (Compêndio de Defensivos Agrícolas, 1999) e utilizados para controle de pragas e doenças da cultura do crisântemo.

\begin{tabular}{lll}
\hline Nome comercial & Ingrediente ativo & Dosagens recomendadas \\
\hline Fungicida & & \\
Alto 100 GR & cyproconazole & $10 \mathrm{a} 15 \mathrm{~mL} / 100 \mathrm{~L}$ água \\
Antracol 700 PM & propinebe & $3,0 \mathrm{~kg} / \mathrm{ha}$ \\
Cercobin 700 PM & tiofanato metílico & $70 \mathrm{~g} / 100 \mathrm{~L}$ água \\
Cuprozeb & mancozebe + oxicloreto de cobre & $200 \mathrm{~g} / 100 \mathrm{~L}$ água \\
Dithane PM & mancozebe & $200 \mathrm{~g} / \mathrm{ha}$ \\
Folicur 200 CE & tebuconazole & $1,0 \mathrm{~L} / \mathrm{ha}$ \\
Rovral SC & iprodione & $100 \mathrm{~mL} / 100 \mathrm{~L}$ água \\
Stratego 250 EC & propiconazole + trifloxistrobina & $400 \mathrm{~mL} / 100 \mathrm{~L}$ água \\
Inseticida & & \\
Actara 250 WG & tiametoxam & $400 \mathrm{~g} / \mathrm{ha}$ \\
Azodrin CE & monocrotofós & $100 \mathrm{~mL} / 100 \mathrm{~L}$ água \\
Confidor 700 Grda & imidaclopride & $100 \mathrm{a} 360 \mathrm{~g} / \mathrm{ha}$ \\
Dicarzol 500 OS & hidrocloreto de formetanato & $150 \mathrm{~g} / 100 \mathrm{~L}$ água \\
Lannate BR & metomil & $100 \mathrm{~mL} / 100 \mathrm{~L}$ água \\
Mesurol 500 SC & metiocarbe & $150 \mathrm{~mL} / 100 \mathrm{~L}$ água \\
Orthene 750 BR & acefato & $100 \mathrm{~g} / 100 \mathrm{~L}$ água \\
Provado 200 SC & imidaclopride & $100 \mathrm{~mL} / 100 \mathrm{~L}$ água \\
Thiodan CE & endosulfan & $1,0 \mathrm{a} \mathrm{1,5} \mathrm{L/ha}$ \\
Trigard 700 PM & ciromazina & $15 \mathrm{~g} / 100 \mathrm{~L}$ água \\
Acaricida & &
\end{tabular}

Para avaliação do crescimento vegetativo, foram utilizadas duas placas com três colônias medindo-se dois diâmetros de cada colônia, com régua graduada, totalizando 6 repetições. Em seguida, as colônias foram recortadas com estilete flambado e colocadas em tubos de ensaio com $10 \mathrm{~mL}$ de uma suspensão autoclavada de água destilada e espalhante adesivo (Tween $80^{\circledR}$ ) a $0,1 \%$. Essa suspensão foi agitada em agitador elétrico de tubos para extração e posterior contagem dos conídios em câmara de Neubauer.

Para o teste de viabilidade, em placa de Petri de plástico com $9 \mathrm{~cm}$ de diâmetro foi colocada uma fina camada de BDA com pentabiótico $(0,5 \mathrm{~g} / \mathrm{L})$. Após a solidificação do meio, cada placa recebeu $0,1 \mathrm{~mL}$ das suspensões fúngicas, provenientes do cultivo com agrotóxicos para a contagem de conídios. As suspensões foram espalhadas com auxílio de uma alça de Drigalsky, flambada e devidamente resfriada. Posteriormente, essas placas foram mantidas por 15 horas em B.O.D. a $25,5 \pm 0,5^{\circ} \mathrm{C}$, umidaderelativa em torno de $70 \%$ e fotoperíodo de 12 horas. Após esse tempo, as placas foram observadas em microscópio com aumento de 400 vezes para a contagem aleatória de 100 conídios, germinados e não germinados, estabelecendo-se uma proporção.
Cada tratamento foi avaliado através de seis repetições tanto para o crescimento radial, quanto para a esporulação e a viabilidade, e o cálculo do fator de compatibilidade dos produtos fitossanitários foi feito através da fórmula proposta por Alves (1998):

$\mathrm{T}=20(\mathrm{CV})+80(\mathrm{ESP}) / 100$, onde:

$\mathrm{T}$ : valor corrigido do crescimento vegetativo e esporulação para a classificação do produto;

$\mathrm{CV}$ : porcentagem de crescimento vegetativo com relação à testemunha;

ESP: porcentagem de esporulação com relação à testemunha.

Os valores de $\mathrm{T}$ foram comparados com os limites estabelecidos de: $0-30$ = muito tóxico; $31-45=$ tóxico; 46-60 = moderadamente tóxico e $>60=$ compatível.

\section{Em estufa}

O ensaio foi realizado na estufa do Laboratório de Controle Biológico do Centro Experimental Central doInstituto Biológicoem Campinas, SP, em condições de temperatura em torno de $27^{\circ} \mathrm{C}$ e umidade relativa de cerca de $70 \%$. Foram usados como tratamento os produtos classificados, no experimento realizado em laboratório, como incompatíveis ao fungo. Esses produtos foram misturados, proporcionalmente, às suas 
dosagens recomendadas, em $150 \mathrm{~mL}$ deágua destilada e inicialmente pulverizados em seis vasos de crisântemo da variedade White Mega Time.

Em seguida, a mesma quantidade de suspensão padronizada $\left(1 \times 10^{7}\right.$ conídios $\left./ \mathrm{mL}\right)$ de JAB 02 foi pulverizada nos mesmos vasos. A testemunha recebeu apenas a suspensão fúngica. Às 0, 24, 48 e 72 horas após a pulverização foram retiradas, aleatoriamente, quatro folhas de cada um dos seis vasos e foi feita uma lavagem com $150 \mathrm{~mL}$ de água destilada esterilizada. Desta suspensão, $0,1 \mathrm{~mL}$ foi transferido e distribuído com alça de Drigalsky em placas de Petri contendo BDA e pentabiótico $(0,5 \mathrm{~g} / \mathrm{L})$. As placas foram incubadas em B.O.D. a $25,5 \pm 0,5^{\circ} \mathrm{C}$, umidade relativa em torno de $70 \%$ e fotoperíodo de 12 horas durante 7 dias. Após esse período foram contadas as colônias de L. lecanii formadas nas placas.

O delineamento experimental dos ensaios foi inteiramente casualizado (DIC), com 6 repetições em cada tratamento, e a análise foi realizada através do programa ESTAT 2.0. Os dados foram submetidos à análise de variância e, na significância desta, foi feito o teste de Tukey a 5\% para a comparação entre as médias.

\section{RESULTADOS E DISCUSSÃO}

\section{Compatibilidade de Lecanicillium lecanii a agrotóxicos}

\section{Em laboratório}

Através da análise estatística pode ser observada diferença entre as testemunhas e todos os fungicidas avaliados em relação ao crescimento vegetativo e reprodutivo, mostrando que os produtos influenciaram tanto no crescimento da colônia quanto na produção dos conídios (Tabela 2).

Os produtos Dithane, Folicur, Antracol, Cercobin e Stratego suprimiram o crescimento e a esporulação do isolado. Nas testemunhas, os valores obtidos foram maiores e diferentes dos tratamentos em que os fungicidas foram adicionados ao meio de cultura (Tabela 2) prejudicando o desenvolvimento do fungo.

Tabela 2-Médias de crescimento, esporulação e viabilidade de conídios do isolado JAB 2 de Lecanicillium lecaniisubmetido a diferentes fungicidas após 16 dias de incubação à temperatura de $25,5 \pm 0,5^{\circ} \mathrm{C}$, umidade relativa em torno de $70 \% \mathrm{e}$ fotoperíodo de 12 horas.

\begin{tabular}{|c|c|c|c|}
\hline Tratamento & Diâmetro $(\mathrm{cm})$ & Conídios $\left(\times 10^{7} / \mathrm{mL}\right)$ & Viabilidade (\%) \\
\hline Testemunha & $4,47 \mathrm{a}$ & $1,78 \mathrm{a}$ & $95,0 \mathrm{a}$ \\
\hline Cuprozeb & $1,83 \mathrm{~b}$ & $0,21 \quad b$ & $91,0 \mathrm{a}$ \\
\hline Dithane & $0,00 \quad c$ & $0,00 \quad c$ & $0,00 \mathrm{~b}$ \\
\hline Folicur & $0,00 \quad \mathrm{c}$ & $0,00 \quad c$ & $0,00 \mathrm{~b}$ \\
\hline Teste F & $31464,51^{* *}$ & $465,24^{* *}$ & $1679,83^{* *}$ \\
\hline C.V. $(\%)$ & 1,85 & 19,62 & 6,90 \\
\hline Tratamento & Diâmetro $(\mathrm{cm})$ & Conídios $\left(\times 10^{7} / \mathrm{mL}\right)$ & Viabilidade (\%) \\
\hline Testemunha & $4,72 \mathrm{a}$ & $0,95 \mathrm{a}$ & 96,0 a \\
\hline Alto 100 máx* & $1,46 \quad b$ & $0,22 \mathrm{~b}$ & $95,8 \mathrm{a}$ \\
\hline Antracol & $0,00 \quad c$ & $0,00 \quad c$ & $0,00 \mathrm{~b}$ \\
\hline Cercobin & $0,00 \quad c$ & $0,00 \quad c$ & $0,00 \mathrm{~b}$ \\
\hline Stratego & $0,00 \quad \mathrm{c}$ & $0,00 \quad \mathrm{c}$ & $0,00 \quad b$ \\
\hline Teste F & $6845,45^{* *}$ & $485,63^{* *}$ & $5251,60 * *$ \\
\hline C.V. $(\%)$ & 4,90 & 19,52 & 4,63 \\
\hline Tratamento & Diâmetro $(\mathrm{cm})$ & Conídios $\left(\times 10^{7} / \mathrm{mL}\right)$ & Viabilidade $(\%)$ \\
\hline Testemunha & $4,28 \mathrm{a}$ & $2,47 \mathrm{a}$ & 99,6 a \\
\hline Alto 100 mín* & $1,49 \quad \mathrm{c}$ & $0,15 \quad c$ & $96,0 \quad b$ \\
\hline Rovral & $3,49 \mathrm{~b}$ & $0,56 \mathrm{~b}$ & 100 a \\
\hline Teste F & $3240,04^{* *}$ & $107,95^{* *}$ & $7,47^{* *}$ \\
\hline C.V. $(\%)$ & 2,00 & 27,51 & 2,02 \\
\hline
\end{tabular}

Médias seguidas de mesma letra na coluna não diferem entre si pelo Teste de Tukey a 5\% de probabilidade.

*máx: concentração máxima, mín: concentração mínima.

**significativo a $1 \%$ de probabilidade pelo Teste $\mathrm{F}$

C.V. = Coeficiente de Variação 
Em relação à viabilidade dos conídios produzidos, a testemunha não diferiu dos tratamentos Cuprozeb, Alto 100 (dosagem máxima) e Rovral e verificou-se que, apesar da influência dos fungi- cidas no crescimento das colônias e também na esporulação do fungo, os conídios produzidos não tiveram sua capacidade de germinação afetada (Tabela 2).

Tabela 3 - Médias de crescimento, esporulação e viabilidade de conídios do isolado JAB 02 de Lecanicillium lecanii submetido a inseticidas e acaricidas após 16 dias de incubação à temperatura de $25,5 \pm 0,5^{\circ} \mathrm{C}$, umidade relativa em torno de $70 \%$ e fotoperíodo de 12 horas.

\begin{tabular}{|c|c|c|c|}
\hline Tratamento & Diâmetro (cm) & Conídios $\left(\times 10^{7} / \mathrm{mL}\right)$ & Viabilidade (\%) \\
\hline Testemunha & $4,77 \mathrm{a}$ & $2,33 \mathrm{a}$ & $97,5 \mathrm{a}$ \\
\hline Confidor máx* & $4,33 \quad \mathrm{c}$ & $1,44 \quad b$ & $98,7 \mathrm{a}$ \\
\hline Confidor mín* & 4,48 bc & $1,23 \mathrm{~b}$ & $99,1 \mathrm{a}$ \\
\hline Orthene & $4,62 \mathrm{ab}$ & $1,56 \mathrm{~b}$ & $98,3 \mathrm{a}$ \\
\hline Teste F & $20,90 * *$ & $9,61^{* *}$ & $1,00^{\text {n.s. }}$ \\
\hline C.V. $(\%)$ & 2,22 & 23,09 & 1,75 \\
\hline Tratamento & Diâmetro (cm) & Conídios $\left(\times 10^{7} / \mathrm{mL}\right)$ & Viabilidade (\%) \\
\hline Testemunha & $4,30 \mathrm{a}$ & $2,64 \mathrm{ab}$ & 99,6 a \\
\hline Thiodan máx* & $0,00 \quad \mathrm{~d}$ & $0,00 \quad c$ & $0,00 \mathrm{~b}$ \\
\hline Thiodan mín* & $1,85 \quad \mathrm{c}$ & $0,24 \quad c$ & 100 a \\
\hline Vertimec máx* & $4,01 \quad b$ & $3,00 \mathrm{a}$ & 99,3 a \\
\hline Vertimec mín* & $4,29 \mathrm{a}$ & $2,24 \quad b$ & 99,3 a \\
\hline Teste F & $1761,52^{* *}$ & $117,59^{* *}$ & $29801,17^{* *}$ \\
\hline C.V. $(\%)$ & 3,86 & 19,46 & 0,79 \\
\hline Tratamento & Diâmetro $(\mathrm{cm})$ & Conídios $\left(\times 10^{7} / \mathrm{mL}\right)$ & Viabilidade $(\%)$ \\
\hline Testemunha & $4,47 \mathrm{a}$ & $1,78 \mathrm{a}$ & 94,6 bc \\
\hline Actara & $4,15 \mathrm{~b}$ & $1,96 \mathrm{a}$ & $92,6 \quad c$ \\
\hline Dicarzol & $4,02 \quad \mathrm{c}$ & $1,44 \mathrm{a}$ & $98,0 \mathrm{ab}$ \\
\hline Mesurol & $3,42 \mathrm{~d}$ & $1,39 \mathrm{a}$ & $99,0 \mathrm{a}$ \\
\hline Teste F & $605,43^{* *}$ & $1,79^{\text {n.s. }}$ & $7,25^{* *}$ \\
\hline C.V. $(\%)$ & 1,09 & 30,29 & 2,78 \\
\hline Tratamento & Diâmetro $(\mathrm{cm})$ & Conídios $\left(\times 10^{7} / \mathrm{mL}\right)$ & Viabilidade (\%) \\
\hline Testemunha & $4,53 \mathrm{a}$ & $1,58 \mathrm{a}$ & $97,3 \mathrm{a}$ \\
\hline Azodrin & $4,27 \quad b$ & $1,60 \mathrm{a}$ & 96,8 a \\
\hline Lannate & $4,53 \mathrm{a}$ & $1,81 \mathrm{a}$ & $96,0 \mathrm{a}$ \\
\hline Teste F & $8,69^{* *}$ & $0,39^{\text {n.s. }}$ & $0,49^{\text {n.s. }}$ \\
\hline C.V. (\%) & 2,79 & 29,29 & 2,45 \\
\hline Tratamento & Diâmetro (cm) & Conídios $\left(\times 10^{7} / \mathrm{mL}\right)$ & Viabilidade (\%) \\
\hline Testemunha & $4,01 \quad b$ & $0,92 \mathrm{a}$ & $98,0 \quad b$ \\
\hline Omite & $4,07 \quad b$ & $0,96 \mathrm{a}$ & $99,3 \mathrm{ab}$ \\
\hline Provado & $4,28 \mathrm{a}$ & $0,84 \mathrm{a}$ & $98,5 \mathrm{ab}$ \\
\hline Trigard & $4,02 \quad b$ & $0,54 \mathrm{~b}$ & 99,6 a \\
\hline Teste F & $13,55^{* *}$ & $14,62^{* *}$ & $4,92^{* *}$ \\
\hline C.V. (\%) & 2,07 & 14,92 & 0,85 \\
\hline
\end{tabular}

Médias seguidas de mesma letra na coluna não diferem entre si pelo Teste de Tukey a $5 \%$ de probabilidade.

*máx: concentração máxima, mín: concentração mínima

**significativo a $1 \%$ de probabilidade pelo Teste $\mathrm{F}$

n.s. = não significativo

C.V. = Coeficiente de Variação 
Esta elevada viabilidade dos conídios produzidos na presença de alguns produtos pode ter ocorrido devidoà degradaçãoe metabolização dos princípios tóxicos das moléculas químicas pelo fungo (Alves 1998).

Resultado semelhante foi encontrado por LOUREIRo et al. (2002) para este mesmo isolado de L. lecanii e os fungicidas Folicur, Dithane e Cercobin em relação ao crescimento e esporulação.

CinTRA (2004) verificou que o produto Folicur também foi responsável pelo não crescimento do isolado IBCB 425 de Metarhizium anisopliae, já no tratamento com o fungicida Alto 100 o desenvolvimento também não foi observado. Resultado semelhante foi obtido por Trama et al. (2001) para L. lecanii. O crescimento e a esporulação não foram observados no tratamento com o produto em que uma das moléculas é o cyproconazole, mostrando a influência negativa do fungicida. Para JAB 02 houve um pequeno crescimento e pouca esporulação quando em contato com o mesmo fungicida (Tabela 2).

A compatibilidade dos fungicidas Antracol e Dithane, em três dosagens diferentes, foi estudada por DuRÁn et al. (2004) para o fungo Beauveria bassiana isolado 447 e foi observado que estes produtos não proporcionaram crescimento deste isolado, sendo esses fungicidas os que causaram os efeitos mais letais entre os produtos avaliados.

Para os inseticidas e acaricidas estudados, o crescimento radial do fungo, cultivado em meio com os produtos Orthene, Vertimec na dose mínima eLannate, não apresentou diferença estatística em relaçãoàs suas respectivas testemunhas. Por outrolado, para o produto Provado observou-se crescimento radial maior que na testemunha diferindo estatisticamente. $\mathrm{O}$ único produto testado em que não se observou crescimento do fungo foi Thiodan na dosagem máxima (Tabela 3).

A produção de conídios na testemunha diferiu da ocorrida nos tratamentos contendo os inseticidas Confidor, nas dosagens máxima e mínima, eOrthene e também diferiu das dosagens máxima e mínima de Thiodan e de Trigard, ou seja, a exposição do fungo a esses produtos causou uma redução na esporulação (Tabela 3).

Os produtos Actara, Dicarzol, Mesurol, Azodrin, Lannate, Omite, Provado e Vertimec, nas duas dosagens utilizadas, não diferiram das respectivas testemunhas (Tabela 3). A presença destes produtos no meio de cultura não afetou a esporulação do fungo. Quanto à viabilidade, observou-se que os conídios não foram afetados pelos agrotóxicos quando produzidos nos meios de cultura com esses compostos, apresentando valores de viabilidade superiores a 92\%, com exceção do produto Thiodan, na dosagem máxima, que não produziu conídios (Tabela 3).

Neves et al. (2001), CAvalcantiet al. (2002), LoureiRo et al. (2002) e ANDALó et al. (2004) verificaram a compatibilidade de alguns produtos ao fungo $B$. bassiana e também observaram que, em relação à esporulação, o produto Actara não diferiu da testemunha, não afetando o desenvolvimento do fungo. Almeida et al. (2003) avaliaram duas doses de Actara (30 e $200 \mathrm{~g} / \mathrm{ha}$ ) para os fungos B. bassiana,Metarhizium anisopliae e L. lecanii e verificaram que a esporulação de $M$. anisopliae não diferiu da testemunha nas duas dosagens. Por outro lado, para L. lecanii a maior dosagem e B. bassiana na menor dosagem diferiram da testemunha, indicando redução na produção de conídios.

Avaliando duas dosagens de Actara, BATISTA FILHO et al. (2001) obtiveram resultados semelhantes para a esporulação dos fungos B. bassiana (IBCB 66), $M$. anisopliae (SPL 358) e Sporothrix insectorum (IBCB 79), sendo que apenas para o fungo $M$. anisopliae, na dosagem mínima, o produto Confidor causou redução na produção de conídios.

Tabela 4 - Valores de T e classificação dos agrotóxicos recomendados e utilizados na cultura do crisântemo quanto à compatibilidade ao fungo Lecanicillium lecanii isolado JAB 02 em laboratório.

\begin{tabular}{|c|c|c|}
\hline Produto & Valores de $\mathrm{T}$ & Classificação* \\
\hline \multicolumn{3}{|l|}{ Fungicida } \\
\hline Alto 100 Máximo & 27,83 & MT \\
\hline Alto 100 Mínimo & 11,80 & MT \\
\hline Antracol & 0 & MT \\
\hline Cercobin & 0 & MT \\
\hline Cuprozeb & 23,92 & MT \\
\hline Dithane & 0 & MT \\
\hline Folicur & 0 & MT \\
\hline Rovral & 34,37 & $\mathrm{~T}$ \\
\hline Stratego & 0 & MT \\
\hline \multicolumn{3}{|l|}{ Inseticida } \\
\hline Actara & 106,65 & $\mathrm{C}$ \\
\hline Azodrin & 99,65 & $\mathrm{C}$ \\
\hline Confidor Máximo & 67,94 & $\mathrm{C}$ \\
\hline Confidor Mínimo & 61,01 & $\mathrm{C}$ \\
\hline Dicarzol & 82,69 & $\mathrm{C}$ \\
\hline Lannate & 111,00 & $\mathrm{C}$ \\
\hline Mesurol & 70,12 & $\mathrm{C}$ \\
\hline Orthene & 72,93 & $\mathrm{C}$ \\
\hline Provado & 94,11 & $\mathrm{C}$ \\
\hline Thiodan Máximo & 0 & MT \\
\hline Thiodan Mínimo & 16,38 & MT \\
\hline Trigard & 66,44 & $\mathrm{C}$ \\
\hline \multicolumn{3}{|l|}{ Acaricida } \\
\hline Omite & 61,30 & $\mathrm{C}$ \\
\hline Vertimec Máximo & 115,45 & $\mathrm{C}$ \\
\hline Vertimec Mínimo & 92,49 & $\mathrm{C}$ \\
\hline
\end{tabular}

*C = compatível, MT = muito tóxico, $\mathrm{T}=$ tóxico. 
Neves etal.(2001)avaliaramtrêsdosagensdiferentes deste mesmo produto e verificaram que os fungos $B$. bassiana (447), M. anisopliae (E9)ePaecilomyces sp.(CNPSo P77) nas dosagens recomendadas também não influenciaram na produção de conídios. A esporulação do isolado UFLA-4 de B. bassiana também não foi influenciada pela utilização de Confidor (CAVALCANTI et al.,2002).

Todos os fungicidas avaliados foram classificados como tóxicos ou muito tóxicos. Por outro lado, entre os inseticidas e acaricidas avaliados somente Thiodan, nas duas dosagens, foi classificado como muito tóxico e os demais produtos foram compatíveis (Tabela 4).

Resultados semelhantes foram obtidos por TAMAI et al. (2002) para o isolado PL 63 de B. bassiana em relação aos fungicidas Cercobin, Dithane, Folicur e Rovral, aos inseticidas Confidor, Orthene e Provado, e ao acaricida Vertimec.

A classificação de Omite e Trigard foi moderadamente tóxico; Dicarzol e Mesurol muito tóxico e Lannate tóxico para o fungo B. bassiana.

Um dos principais fatores envolvidos no nível de toxicidade dos produtos fitossanitários aos fungos entomopatogênicos é o modo de ação do ingrediente ativo. Moléculas como mancozebe pertencem ao grupo dos fungicidas protetores, que se caracterizam por apresentarem atividades em múltiplos sítios de ação, afetando grande número de processos vitais defungos fitopatogênicos (GHINI;KIMATI, 2000). Assim, verificousequeessa molécula não foi seletiva a L. lecanii,JAB02.

Os produtos Confidor e Provado que possuem o mesmo princípio ativo (imidaclopride) foram compatíveis a L. lecanii, JAB 02 (Tabela 4) mostrando que não houve efeito desta molécula sobre o fungo, apesar da diferença na formulação do produto.

O inseticida Thiodan foi classificado como muito tóxico (Tabela 4), resultado que concorda com os obtidos por BATISTA FILHO et al. (2001) em seu trabalho de compatibilidade com os fungosB. bassiana (isolado IBCB 66), M. anisopliae (isolado SPL 358) e Sporothrix insectorum (isolado IBCB 79), que foram classificados como incompatíveis. Entretanto, para alguns produtos, os resultados foram diferentes. Confidor, que foi classificado como compatível para L. lecanii, JAB 02, também foi compatível para $S$. insectorum, entretanto para B. bassiana foi moderadamente tóxico e para $M$. anisopliae foi tóxico (Tabela 4).

Tabela 5 - Número médio de colônias do isolado JAB 02 de Lecanicillium lecanii formadas de suspensões obtidas das lavagens de folhas de crisântemo tratadas com agrotóxicos após 7 dias de cultivo à temperatura de $25,5 \pm 0,5^{\circ} \mathrm{C}$, umidade $^{2}$ relativa em torno de $70 \%$ e fotoperíodo de 12 horas.

\begin{tabular}{|c|c|c|c|c|}
\hline \multirow[t]{2}{*}{ Tratamento } & \multicolumn{4}{|c|}{ Tempo de coleta } \\
\hline & 0 hora $^{1}$ & 24 horas $^{1}$ & 48 horas $^{1}$ & 72 horas $^{1}$ \\
\hline Testemunha & $312 \mathrm{~b}$ & $91 \mathrm{a}$ & $72 \mathrm{a}$ & $58 \mathrm{a}$ \\
\hline Antracol & $25 \mathrm{c}$ & $1 \mathrm{~d}$ & $0 \quad d$ & $0 \quad \mathrm{c}$ \\
\hline Cercobin & $287 \mathrm{~b}$ & $46 \mathrm{~b}$ & $34 \mathrm{bc}$ & $17 \mathrm{~b}$ \\
\hline Dithane & $22 \mathrm{c}$ & $0 \quad \mathrm{~d}$ & $0,6 \quad d$ & $0 \quad c$ \\
\hline Folicur & $330 \mathrm{~b}$ & $20 \mathrm{c}$ & $23 \mathrm{c}$ & $5 c$ \\
\hline Rovral & $500 \mathrm{a}$ & $61 \mathrm{ab}$ & $51 \mathrm{ab}$ & $52 \mathrm{a}$ \\
\hline Stratego & $214 \mathrm{~b}$ & $1 \mathrm{~d}$ & $0,3 \quad d$ & $0 \quad c$ \\
\hline Teste F & $58,80 * *$ & $68,75^{* *}$ & $51,78^{* *}$ & $58,67^{* *}$ \\
\hline C.V.(\%) & 15,25 & 22,18 & 25,09 & 27,04 \\
\hline Tratamento & 0 hora $^{2}$ & 24 horas $^{2}$ & 48 horas $^{1}$ & 72 horas $^{1}$ \\
\hline Testemunha & $241 \mathrm{ab}$ & $89 a$ & $47 \mathrm{a}$ & $11 \mathrm{a}$ \\
\hline Alto 100 mínimo & $246 \mathrm{a}$ & $78 \mathrm{a}$ & $21 \mathrm{c}$ & $7 \mathrm{ab}$ \\
\hline Alto 100 máximo & $263 \mathrm{a}$ & $86 \mathrm{a}$ & $39 \mathrm{ab}$ & $14 \mathrm{a}$ \\
\hline Cuprozeb & $179 \mathrm{c}$ & $5 \mathrm{c}$ & $4 \quad \mathrm{~d}$ & $2 b$ \\
\hline Thiodan mínimo & $152 \mathrm{c}$ & $37 \mathrm{~b}$ & $26 \mathrm{bc}$ & $12 \mathrm{a}$ \\
\hline Thiodan máximo & $186 \mathrm{bc}$ & $21 \mathrm{bc}$ & $17 \mathrm{c}$ & $14 \mathrm{a}$ \\
\hline Teste F & $11,02 * *$ & $86,71^{* *}$ & $44,88^{* *}$ & $6,27 * *$ \\
\hline C.V.(\%) & 15,50 & 18,17 & 13,05 & 24,84 \\
\hline
\end{tabular}

${ }^{1}$ Dados originais na tabela, porém, transformados em $\sqrt{x+1}$ para a análise estatística.

${ }^{2}$ Dados originais na tabela e não transformados para a análise estatística.

Médias seguidas de mesma letra na coluna não diferem entre si pelo Teste de Tukey a 5\% de probabilidade.

**significativo a $1 \%$ de probabilidade pelo Teste $\mathrm{F}$

C.V.= Coeficiente de Variação 
Em experimento de compatibilidade realizado por LOUREIRO et al. (2002), Dithane e Folicur 200 CE foram considerados muito tóxicos, concordando com os resultados obtidos no presente trabalho.

Uma estratégia para reduzir o efeito restritivo dos fungicidas à utilização de fungos entomopatogênicos é a adoção conjunta de diversas medidas como uso de mudas sadias e variedades resistentes, manejo da irrigação, remoção de mudas e plantas doentes (ZAMBolim et al., 1999). Outra maneira seria a aplicação do fungicida apenas onde a doença se encontra, ou seja, nos focos, efazer a pulverização do fungicida em intervalos de tempo suficientes para não coincidir com as fases mais suscetíveis da interação patógeno e hospedeiro tempo este suficiente para que o conídio germine e invada o hospedeiro (TAMAI et al., 2002).

\section{Em estufa}

A sobrevivência dos propágulos do fungo pode variar em função da superfície e do tipo de substrato em que são aplicados (ar, solo, água, folha, hospedeiro, produto químico) (McCor et al., 1988 citado por TANADA; KAYA, 1992). Desta forma, houve um decréscimo do inóculo de L. lecanii nas folhas avaliadas à medida que o tempo de coleta aumentou (Tabela 5).

No tratamento com o fungicida Rovral, o número de colônias formadas foi superior às da testemunha no tempo de 0 hora e não diferiu desta nos outros três tempos avaliados. Já os fungicidas Cercobin, Folicur, Stratego, Alto 100, nas duas dosagens, e Thiodan, na dosagem máxima, não diferiram da testemunha no tempo de 0 hora (Tabela 5).

Notempode 24 horas, as duas dosagens de Alto 100 não diferiram da testemunhae, $\mathrm{em} 48$ horas, ofungicida Alto 100 máximo foi semelhante à testemunha. Já no tempo de 72 horas alguns produtos não diferiram da testemunha como as duas dosagens de Thiodan e Alto 100(Tabela5), indicandoquenãohouveinfluência dos produtos no crescimento do fungo.

Após 48 horas, pode ser observado que Rovral e a testemunha são os tratamentos que ainda proporcionam maior número de colônias formadas e isso se repete no tempo de 72 horas. Pode ser notado que, no decorrer do período em que foram realizadas as coletas, houve uma diminuição do número de colônias em todos os tratamentos (Tabela 5).

Alguns produtos foram mais drásticos em relação à toxicidade, os quais apresentaram poucas colônias e impediram a sua formação nos tempos posteriores, comoosfungicidas Antracol, Dithane, Folicur,Stratego e Cuprozeb (Tabela 5).

Em experimento objetivando o planejamento de aplicações do fungicida Benomil e do fungo L. lecanii, na forma do produto comercial Vertalec ${ }^{\circledR}$, em estufas de crisântemo, GARDNERet al. (1984) verificaram que o número de colônias formadas imediatamente após os tratamentos foi mais alto. Os autores verificaram que a aplicação de Benomil, depois da aplicação do fungo, resultou em total inibição das unidades formadoras de colônias. Já para a aplicação do fungicida antes do fungo, a atividade do fungicida não foi totalmente deletéria. A atividade de Vertalec ${ }^{\circledR}$ não foi inibida por Benomil quando o fungicida foi aplicado 7 dias ou mais antes do fungo.

Almeida et al. (2003) verificaram a compatibilidade, em campo, de defensivos agrícolas utilizados na cultura docafé para ofungo B. bassianae M. anisopliae. Osautores verificaram que não houve diferença estatística para os tratamentos Verdadero 20GR (500 g/ha), Verdadero 20GR (500 g/ha) + B. bassiana ( $1 \mathrm{~kg} / \mathrm{ha})$, Actara 250WG (200 g/ha), Actara 250WG (200 g/ha) + B. bassiana, B. bassiana, Thiodan CE (2 L/ha), Thiodan CE (2 L/ha) + B. bassiana e testemunha nas contagens de colônias nas folhas e em frutos, ou seja, os produtos não influenciaram na formação das colônias de $B$. bassiana, que foi aplicada, e de M. anisopliae por ocorrência natural.

Batista FilHo et al. (2003) avaliaram, na cultura da soja, lagartas de Anticarsia gemmatalis e adultos de Cerotoma spp. colonizados por Nomuraea rileyi e $B$. bassiana, respectivamente. O potencial de inóculo dos fungos não foi reduzido pela ação dos inseticidas Actara Mix, Curyom e Thiodan, pois, em todos os tratamentos e tempos avaliados, foi verificada a presença de insetos mortos pela ação dos patógenos, não diferenciando da testemunha.

A complementação entre os ensaios de compatibilidade realizados em laboratório e na estufa torna-se importante porque a condição de contato entre produto e fungo, em condição de estufa, não é tão extrema. No caso do fungicida Rovral que, em laboratório, foi muito tóxico; em estufa possibilitou o crescimento de colônias do fungo em número até superior ao da testemunha, indicando a possibilidade de uso alternado entre fungicida e fungo.

\section{CONCLUSÕES}

Todos os fungicidas e o inseticida Thiodan nas duas dosagens utilizadas são tóxicos a L. lecanii, JAB 02 e os demais produtos são compatíveis, em laboratório.

Os fungicidas Rovral e Alto 100 são compatíveis ao Lecanicillium lecanii, JAB 02, em estufa, quando aplicados previamente ao fungo.

\section{AGRADECIMENTOS}

À Coordenação de Aperfeiçoamento de Pessoal de Nível Superior (CAPES) pela concessão da bolsa de doutorado. 
REFERENCIAS

ALMEIDA, J.E.M.; BATISTA FILHO, A.; LAMAS, C.; LEITE, L.G.; TRAMA, M.; SANO, A.H. Avaliação da compatibilidade de defensivos agrícolas na conservação de microrganismos entomopatogênicos no manejo de pragas do cafeeiro. Arquivos do Instituto Biológico, São Paulo, v.70, n.1, p.79-84, 2003.

ALVES, S.B. Fungos entomopatogênicos. In: Controle microbiano de insetos. Piracicaba: FEALQ, 1998. p.289-381.

ANDALÓ, V.; MOINO JUNIOR, A.; SANTA-CECÍLIA, L.V.C.; SOUZA, G.C. Compatibilidade de Beauveria bassiana com agrotóxicos visando o controle da cochonilha-da-raiz-do-cafeeiro Dysmicoccus texensis Tinsley (Hemiptera: Pseudococcidae). Neotropical Entomology, v.33, n.4, p.463-467, 2004.

BATISTA FILHO, A.; ALMEIDA, J.E.M.; LAMAS, C. Effect of thiamethoxam on entomopathogenic microorganisms. Neotropical Entomology, v.30, n.3, p.437-447, 2001.

BATISTA FILHO, A.; RAMIRO, Z.A.; ALMEIDA, J.E.M.; LEITE, L.G.; CINTRA, E.R.R.; LAMAS, C. Manejo integrado de pragas em soja: impacto de inseticidas sobre inimigos naturais. Arquivos do Instituto Biológico, São Paulo, v.70, n.1, p.61-67, 2003.

BENZ, G. Synergism of micro-organisms and chemical insecticides. In: BURGES, H.D.; HUSSEY, N.W. (Ed.). Microbial control of insects and mites. New York: Academic Press, 1971. p.327-355.

BOMAN, H.G. Insect responses to microbial infections. In: BURGES, H.D. (Ed.). Microbial control of pest and plant diseases, 1970-1980. New York: Academic Press, 1980. p.769-784.

CAVALCANTI, R.S.; MOINO JUNIOR, A.; SOUZA, G.C.; ARNOSTI, A. Efeito de produtos fitossanitários fenpropatrina, imidaclopride, iprodione, e tiametoxam sobre o desenvolvimento do fungo Beauveria bassiana (Bals.) Vuill. Arquivos do Instituto Biológico, São Paulo, v.69, n.3, p.17-22, 2002.

CINTRA, E.R.R. Avaliação de Metarhizium anisopliae (Metsch.) Sorok. para o controle de Fidicinoides pronoe (Hemiptera: Cicadidae) e sua compatibilidade com produtos fitossanitários utilizados na cultura do café. 2004. $46 f$. Dissertação (Mestrado em Proteção de Plantas) Faculdade de Ciências Agronômicas, Botucatu, 2004.

\section{COMPÊNDIO DE DEFENSIVOS AGRÍCOLAS. Guia}

Prático de produtos fitossanitários para uso agrícola. $5 \mathrm{ed}$. São Paulo: Andrei, 1999. 672p.

DURÁN, J.; CARBALLO, M.; HIDALGO, E. Efecto de fungicidas sobre la germinación y el crecimiento de Beauveria bassiana. Manejo Integrado de Plagas y Agroecología, v.71, p.73-78, 2004.
ER, M.K., GÖKÇE, A. Effects of selected pesticides used against glasshouse tomato pests on colony growth and conidial germination of Paecilomyces fumosoroseus. Biological Control, v.31, p.398-404, 2004.

FONTANA, C.F. Crisântemum. Florarte Atualize, n.1, p.46, 2005.

GARDNER, W.A.; OETTING, R.D.; STOREY, G.K. Scheduling of Verticillium lecanii and Benomyl applications to maintain aphid (Homoptera: Aphididae) control chrysanthemums in greenhouse. Journal of Economic Entomology, v.77, n.2, p.514-518, 1984.

GHINI, R.; KIMATI, H. (Ed.). Resistência de fungos a fungicidas. Jaguariúna: Embrapa Meio Ambiente, 2000. $78 \mathrm{p}$.

HALL, R.A. The fungus Verticillium lecanii as a microbial insecticide against aphids and scales.In: BURGES, H.D. (Ed.). Microbial control of pests and plant diseases 1970-1980. London: Academic Press, 1981. p.483-498.

LOUREIRO, E.S.; MOINO JUNIOR, A.; ARNOSTI, A.; SOUZA, G.C. Efeito de produtos fitossanitários químicos utilizados em alface e crisântemo sobre fungos entomopatogênicos. Neotropical Entomology, v.31, n.2, p.263-269, 2002.

MCCOY, C.W.; SAMSON, R.A.; BOUCIAS, D. G. Entomogenous fungi. In: IGNOFFO, C.M.; MANDAVA, N.B.(Ed.). Handbook of natural pesticides. Microbial insecticides, part $A$ : entomogenous protozoa and fungi. Boca Raton: CRC Press, 1988. v.5, p.151-236. apud TANADA, Y.; KAYA, H.K., 1992. p.318-387.

NEVES, P.M.O.J.; HIROSE, E.; TCHUJO, P.T.; MOINO JUNIOR, A. Compatibility of entomopathogenic fungi with neonicotinoids insecticides. Neotropical Entomology, v.30, n.2, p.263-268, 2001.

NILSON. U.; GRIPWALL, E. Influence of the technique on the viability of the biological controls agents Verticillium lecanii and Steinernema feltiae. Crop Protection, v.18, p.53-59, 1999.

VAN DER SCHAAF, D.A.; MALAIS, M.; RAVENSBERG, W.J. The use of $V$. lecanii against whitefly and thrips in glasshouse vegetables in Netherlands. In: INTERNATIONAL COLLOQUIUM ON INVERTEBRATE PATHOLOGY AND MICROBIAL CONTROL, 5., 1990, Adelaide. Proceedings. Adelaide: 1990. p.391.

TAMAI, M.A.; ALVES, S.B.; LOPES, R.B.; FAION, M.; PADULLA, L.F.L. Toxicidade de produtos fitossanitários para Beauveria bassiana (Bals.) Vuill. Arquivos do Instituto Biológico, São Paulo, v.69, n.3, p.8996, 2002. 
TANADA, Y.; KAYA, H.K. Fungal infections. In: . Insect pathology. San Diego: Academic Press, 1992. p.318-387.

TRAMA, M.; ALMEIDA, J.E.M.; BATISTA FILHO, A.; LAMAS, C. Compatibilidade dos inseticidas e fungicidas utilizados no controle de pragas do cafeeiro aos fungos Beauveria bassiana, Metarhizium anisopliae e Verticillium lecanii. Arquivos do Instituto Biológico, São Paulo, v.68, 2001. Suplemento. Trabalho apresentado na REUIÃO ANUAL DO INSTITUTO BIOLÓGICO, 14., 2001. Resumo 36. 1-CD ROM.

ZAMBOLIM, L.; COSTA, H.; LOPES, C.A.; VALE, F.X.R. Doenças das hortaliças em cultivo protegido. Informe Agropecuário, v.20, n.200/201, p.114-125, 1999.

Recebido em 22/5/07

Aceito em 16/5/08 